\title{
The Stereotypical Scientist
}

by

\section{HUDSON}

Research Centre, King's College, Cambridge

\author{
Do schoolboys regard the scientist as dull? A recent study may \\ be relevant.
}

At the age of 15 or 16 most able English schoolboys fuce a choice between the arts and sciences. Boys who specialize in science are known to differ both intellectually and in personality from those who specialize in the $\operatorname{arts}^{1,2}$ Scientists, for example, have been found to be reticent in their expression of emotion ${ }^{2}$ and to deal with personal relationships in an inbibited fashion ${ }^{3}$.

Further evidence suggests that there exist certain stereotypical beliefs about the personal characteristics of arts men and scientists. American students see the scientist as highly intelligont and masculine, but lacking in sensitivity and concern for people; as gaining satisfaction from his work, but having a shallow personal life ${ }^{4}$. Previous research on this topic, however, suffors a central weakness. It does not indicate whether such attitudes are shared by potential arts and science specialists alike.

The first part of the present enquiry was based on the "semantic differential"s. The individual rates a number of typical figures (for example, Mathematician, Poet) on pairs of adjectives (such as exciting/dull, dopendable/ undependable), each rating being on a seven-point scale (for example, "extremely exciting" to "extremely dull"). The sample ( $n=390)$ was limited to 13,15 and 17 year old boys of high academic ability, drawn from two schools, one public boarding and ono grammar.
The prosent data confirm the American result. The typical physical scientist emerges as entirely distinct from typical figures in the vorbal arts. Table 1 shows one contrast, representative of the data as a whole: that between the Physicist and the Novelist (of twenty mean ratings given, eighteen are statistically significant: $P<0 \cdot 05)$. The semantic differential also includes a number of typical women and, again, American findings are borne out. Compared, for example, with the wife of the Novelist, Doctor or Barrister, the wife of the Research Scientist is seen as dull and plain.

The sample was thon broken down by academic speciality, and two sub-groups formed: (i) arts specialists, taking a sixth form course in English, history or modern languages $(n=75)$, and (ii) physical science specialists, studying mathematics, physics and chemistry $(n=67)$. Their responses were then compared.

Fig. I shows the contrast between Novelist and Physicist, as seen by arts specialists and by young physical scientists. Despito "haloes" of approval for members of their own speciality, the attitudes of the two groups are strikingly similar. Both groups agreo that the Novelist is the more imaginative, warm and exciting; the Physicist the more dependable, hard and hard-working. (Of differences plotted, nineteen deviate significantly from

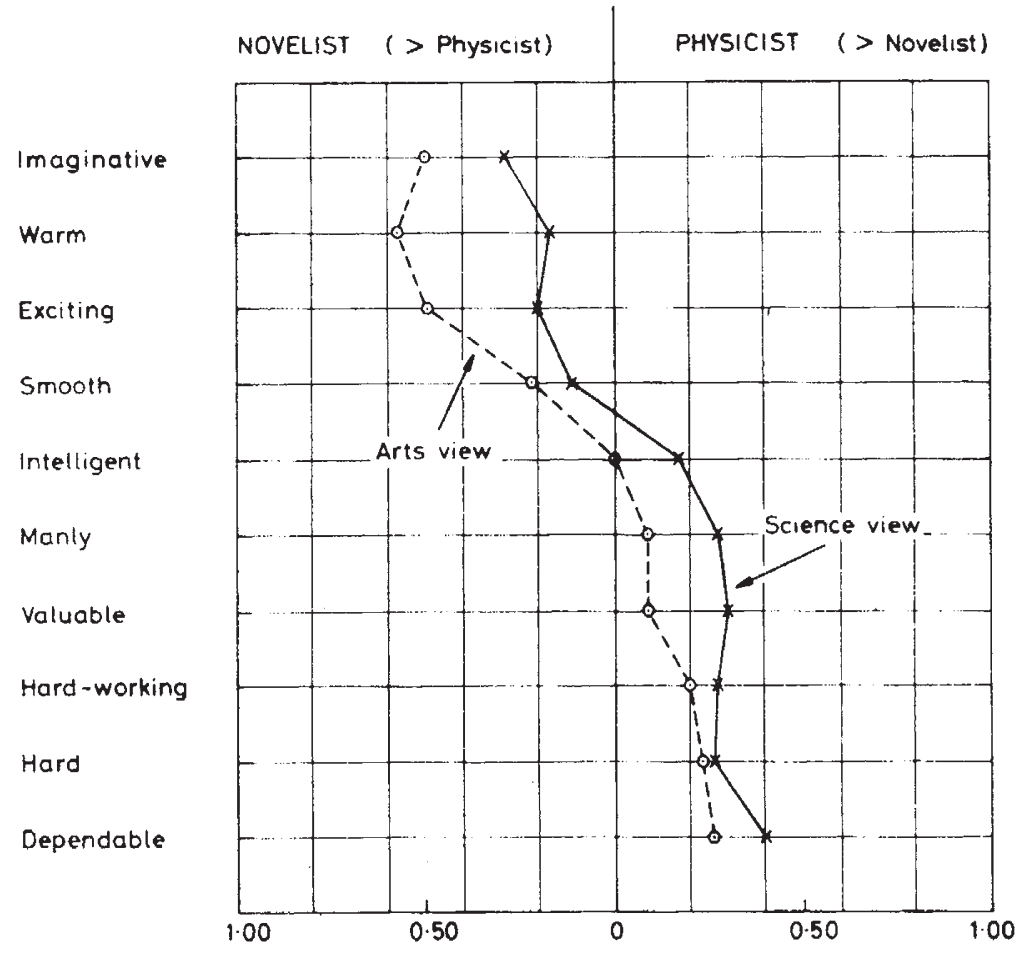

Fig. 1. Differences between "the Novelist" and "the Physicist", as seen by young arts specialists $(n=75)$ and by young physical seientista
$(43=67)$. $(n=67)$. Each point represents a difference between two mean ratings on the semantic differential- 
Table 1. QUALITIES ATTRIBUTED BY SCHOOLBOXS $(n=390)$ TO 'TWO FIGURES:

"THE NOV
Novelist
Imaginative
Warm
Intelligent
Exciting
Valuable
Undependable
Smooth
Soft
Feminine

0.86
$0 \cdot 48$
$0 \cdot 41$
$0 \cdot 38$
$0 \cdot 31$
$0 \cdot 30$
$0 \cdot 19$
$0 \cdot 19$
$0 \cdot 12$
0.04

$\quad$ Physicist
Valuable
Intelligent
Hard-working
Dull
Dependable
Cold
Hard
Manly
Rough

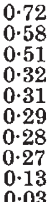

Unimaginative $\quad 0.03$

Mean ratings on the semantic differential converted to a soale from zero to 1.00 , where zero represents the absence of a given quality, and 1.00 the maximum possible rating upon it.

zero: $P<0.05)$. Furthermore, the two groups agree closely in their rank ordering of discriminative adjectives from "warm" to "dependable" for the arts group, and from "imaginative" to "dependable" for the young scientists: $r_{s}=0.88, P<0.01$.

Analogous results emerge from the contrast between the wife of the Novelist and the wife of the Research Scientist. Both groups agree that, of the two, the wife of the Novelist is significantly the more exciting, feminine, soft, imaginative; while the wife of the Research Scientist is the more dependable. (In each case, $P<0.05$.) Agreement in the rank ordering of adjectives is again high: $r_{s}=0.9 \mathrm{I}$, $P<0.01$. Substantially, the relations shown in Fig. 1 hold true for boys of all academic specialities, and for all typical figures relevant to the arts/science choice. Furthermore, such stereotyped attitudes are found as pronounced among unspecialized 13 year olds as among specialists of 17 .

A clear implication of these data is that adult scientists are seen by both future arts and science specialists as leading dull personal lives. It was to explore this particular inference that a "typical graduates questionnaire" was devised. A typical male arts graduate and a typical male science graduate are compared in the light of thirty characteristics, some general (such as "competitive with others") and others specific (such as "wears fashionable clothes"). Responses are on a five-point scale, ranging from "arts graduate much more likely" to "science graduate much more likely". The sample used was of similar composition to the first. Each item in the questionnaire yielding a significant rating for both arts and science specialists is given in Table $2(P<0.05)$. These results suggest that both groups see the typical arts graduate as the more pleasure-seeking and irresponsible figure, and the typical science graduate as the more puritanical. The agreement between the rank ordering of items is again high: for all thirty items, $r_{s}=0.82, P<0.01$.

It might be protested that such evidence is trivial: arts and science specialists may differ in the value they
Table 2. COMPARISON OF QUALITIES ATTRIBUTED TO THE "TYPICAE ARTS SPECIALISTS $(n=79)$ AND BY YOUNG PHYSIOAL SOIENTISTE $(n=59)$ Young arts specialists' view Young physical scientists' view Arts Wears fashionable clothes 0.62 Wears fashionable clothes $\quad 0.57$ $\begin{array}{llll}\text { Arts } & & \\ \text { Graduate Sociable } & 0.61 & \text { Gets divorced } & \mathbf{0 . 3 9}\end{array}$

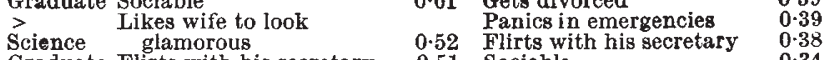

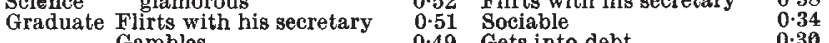
$\begin{array}{llll}\text { Gambles } & 0.49 & \text { Gets into debt } & 0 \cdot 30\end{array}$ Likes expensive restaurants 0.42 Gambles 0.28 $\begin{array}{llll}\text { Gets divorced } & 0.36 & \text { Likes expensive restaurants } 0.25 \\ & 0.30 & \text { Likes wifo to look } & 0.23\end{array}$ Has fast car Panics in emergencies

Science Faithful to wife 0.19 Embarrassed (for example, about sex) (for example, about sex) Grts Competitive at work

0.24
0.25
about sex 0.25 Faithful to wife 0.58 Competitive at work Competitive at work

Mean ratings on the "typical graduates questionnaire" converted to a scale from zero to 1.00 , where zero represents the absence of a given quality and 1.00 the maximum possible rating upon it.

attach to such adjectives as "warm" and "cold". Further evidence from the semantic differential refutes this. Arts and science specialists agree overwhelmingly in attributing the adjectives intelligent, imaginative, exciting, warm, dependable and valuable to figures defined in the test as "good" (for example, Good Father, Good Teacher, Good Friend).

It seems, in summary, that whatever their speciality, the attitudes of boys towards the arts and sciences are influenced by a common set of preconceptions. Psychologically, this finding is intriguing. Large numbers of boys choose careers in the physical sciences, believing as they do so that the personal life of the adult scientist is unexciting. This choice may represent a reluctant compromise, but previous research suggests that it will frequently be made gladly, and even with a sense of relief ${ }^{2}$. Such stereotyped preconceptions may also help to explain why, contrary to predictions of a historical or economic nature, the proportion of able children recruited to the physical sciences in Great Britain has failed to increase since 1960 and may indeed have de. creased $^{6}$. It remains unclear, however, where boys' stereotyped ideas originate and to what extent they are open to change.

These results arise from a programme of research supported by the Nuffield Foundation.

${ }^{1}$ Hudson, L., Brit. J. Educ. Psychol., 33, 120 (1963).

${ }^{2}$ Hudson, L., Contrary Imaginations (Methuen, London, 1966).

${ }^{3}$ Roe, A., Psychological Monogr., 67, No. 352 (1953).

${ }^{4}$ Beardslee, D. C., and O'Dowd, D. D., in The American College (edit. by Sanford, $\dot{\mathrm{N}}$. (Wiley, London, 1962).

'Osgood, C. E., Suci, G. J., and Tannenbaum, P. H., The Measurement of Meaning (University of Illinois, Urbana, 1957).

${ }^{6}$ Phillips, C. M., Times Educational Supplement (November 19, 1965).

(Continued from page 227)

\section{THE NIGHT SKY IN FEBRUARY}

All times are in Universal Time

$\begin{array}{lrcc}\text { MooN } & & \text { ConJonotions WITH THE MooN } \\ \text { New Moon } & 9 \mathrm{~d} 11 \mathrm{~h} & \text { Venus } & 11 \mathrm{~d} 09 \mathrm{~h}, 3^{\circ} \mathrm{N} . \\ \text { Full Moon } & 24 \mathrm{~d} 18 \mathrm{~h} & \text { Mars } & 28 \mathrm{~d} 15 \mathrm{~h}, 2^{\circ} \mathrm{N} \text {. } \\ & & \text { Jupiter } & 21 \mathrm{~d} 23 \mathrm{~h}, 4^{\circ} \mathrm{S} \text {. } \\ & & \text { Saturn } & 12 \mathrm{~d} 13 \mathrm{~h}, 1^{\circ} \mathrm{N} .\end{array}$

Planets

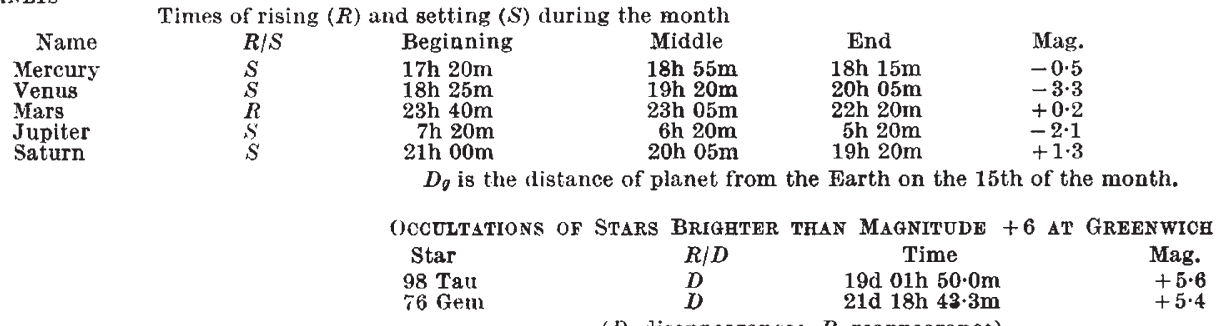

Other Phenomena

$25 \mathrm{~d} 20 \mathrm{~h}$ Uramus $3^{\circ} \mathrm{S}$. of Moon

(D), disappearance; $R$, reappearance)

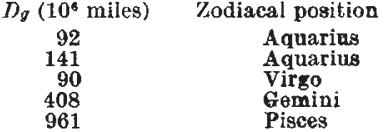

